\title{
Accidents on board merchant ships. Suggestions based on Centro Internazionale Radio Medico (CIRM) experience
}

\section{Paolo Napoleone}

Research Department, International Radiomedical Centre (CIRM), Rome, Italy

\begin{abstract}
Background: This statistical study was performed to find out the occurrence of accidents on board ships assisted by Centro Internazionale Radio Medico (CIRM) during the years 2010-2015, with the aim of providing suggestions in accident prevention, based on such a wide experience.

Materials and methods: The case histories of CIRM in the years 2010-2015 were examined. The total number of accidents per year was calculated and compared as a percentage with the total number of cases assisted by CIRM per year.

Results: The incidence of accidents on board in these years ranged between $14.4 \%$ and $18.4 \%$ of total cases assisted per year, which is constantly increasing. The most common injuries on board among cases treated by CIRM were contusions and wounds. Also burns and eye injuries were significantly represented. Multiple injuries and head injuries were found to be the most frequent cause of death on board due to an accident. Conclusions: More information on the occurrence and type of accidents and on the body injured areas should represent the basis for developing strategies and campaigns for their prevention.
\end{abstract}

(Int Marit Health 2016; 67, 1: 21-23)

Key words: maritime health, accidents, occupational hazards, seafarers, safety, CIRM

\section{INTRODUCTION}

The Centro Internazionale Radio Medico (CIRM) is the Italian Telemedicine Maritime Assistance Service (TMAS) and from its headquarter in Rome provides medical advice to ships worldwide. It was established in 1935, and nowadays the number of cases treated is the largest when compared with any other similar centre in the world (more than 4000 per year) [1]. CIRM, and its Research Department (formerly Studies Section), historically has been carrying out many studies in the area of accidents on board ships, since the late 50s [2-4]. That's why CIRM's case histories represent an outstanding source of information to lead to a deeper understanding of the dimensions and features of accidents on board merchant ships [4].
In the present study a statistical analysis was performed on the occurrence of accidents on board ships assisted by CIRM for the years 2010-2015, with the aim of providing useful suggestions in prevention of accidents, based on such a wide experience.

\section{MATERIALS AND METHODS}

The case histories of CIRM in the years 2010-2015 were revised. The total number of accidents per year was calculated and compared as a percentage with the total number of cases assisted by CIRM per year.

The incidence of different types of injuries (multiple injuries, contusions, wounds, eye injuries, head injuries, sprains and dislocations, burns, amputation of fingers or 
Table 1. Total number of cases assisted by International Radiomedical Centre (CIRM) in 2010-2014 and accidents occurring in these 5 years of observation

\begin{tabular}{llll}
\hline Year & No. cases & No. accidents & Percent \\
\hline 2010 & 2528 & 465 & $18.4 \%$ \\
2011 & 2659 & 481 & $18.1 \%$ \\
2012 & 3206 & 582 & $18.1 \%$ \\
2013 & 3508 & 602 & $17.1 \%$ \\
2014 & 4091 & 590 & $14.4 \%$ \\
2015 & 4215 & 693 & $16.5 \%$
\end{tabular}

Table 2. Type of accidents requiring assistance of International Radiomedical Centre (CIRM) in 2210-2014

\begin{tabular}{ll}
\hline Type of accidents & Per cent \\
\hline Multiple injuries & $2.5 \%$ \\
Contusions & $29.9 \%$ \\
Fractures & $6.5 \%$ \\
Wounds & $28.8 \%$ \\
Eye injuries & $8.0 \%$ \\
Head injuries & $4.8 \%$ \\
Sprains - dislocations & $3.7 \%$ \\
Burns & $7.7 \%$ \\
Amputation of fingers & $4.3 \%$ \\
Exposure to toxic agents & $2.7 \%$ \\
Heat strokes & $1.1 \%$
\end{tabular}

phalanxes, exposure to toxic agents, heat strokes) was also pointed out.

Data obtained from these analyses were compared with those resulting from previous studies carried out by CIRM and analysed statistically by analysis of variance (ANOVA).

\section{RESULTS AND DISCUSSION}

The number of cases treated by CIRM and of accidents on board in the years considered, as well as the related percentages, is summarised in Table 1. As shown, a constant increase in the total number of cases treated per year as well as in the absolute number of accidents is noticeable. This indicated that the occurrence of accidents on board is still relevant and a reduction of this trend is yet to be observed, despite the technical progress in naval engineering and the increased awareness of the problem.

The incidence of the different types of injuries is summarised in Table 2. As shown, contusions and wounds were in the order the accidents occurring more often on board ships we have assisted.

As expected, minor injuries play the main role. Contusions and wounds can occur in nearly any circumstance on board, and are commonly unrelated to any specific cause related to daily activities or work on board. A minor fall, a collision, and the use of a tool are the most frequent causes of contusions and wounds on board.

Unlike these minor injuries, other types of injuries are more specifically related to some aspect of life and work on board. Multiple injuries and fractures result from a fall from a certain height or along stairs; burns are caused by boiling steam/fluids or flame returning the engine room but also in the kitchen. Eye injuries are usually the result of a foreign body (commonly rust or coal particles), splashes of acid or other chemicals; amputation of fingers or part of them is caused most commonly by sudden closing of metal-locker doors. Acute gas intoxication can occur by exposure to oil vapours; heat strokes take place in the high temperature of the engine rooms. It is worthy to point out that multiple injuries and head injuries (and exposure to toxic agents to a lesser extent) are the most common cause of death on board due to an accident. An extensive report of deaths on board in the period 1986-2010 published by CIRM [5] revealed that deaths on board (that represent $1.3 \%$ of cases treated in the period considered) are due to an accident in about one third of cases.

A comparison between data from the present study and those from previous investigations [2-4] cannot lead to any definite conclusion, due to the time lapse and the fundamental changes that have occurred in the meantime. Previous studies carried out by CIRM covered the period 1962-1981, when a percentage of accidents spanning between $12.8 \%$ and $20.2 \%$ was observed. This percentage is surprisingly similar to that observed in the current years, although related to a total number of patient treated that was 4-fold smaller at that time. Also the percentage of the different types of injury considered in the older investigations is not very different from the current one (data not shown).

Causes of accidents on board can be classified as environmental and human [6]. The ship is a peculiar and not comfortable environment where crews live and work $24 \mathrm{~h}$ a day. Many features of this environment can cause or contribute in causing accidents: the instability of ship, the presence of 
restricted spaces with uneasy access and narrow passages, floor obstacles, moving mechanical parts (features that may easily lead to falls and collisions). The effect of vibrations, noise, carrying chemicals and toxic substances, macro- and micro-climate factor must be considered. The risk of accident is higher if there is a lack of maintenance and periodical supervision leading to any type of malfunction.

The "human" causes of accidents include any aspect related to one's physical or mental health causing a significant decrease in physical/mental efficiency and performance during work $[6,7]$. According to International Maritime Organisation (IMO) a "human factor" is responsible, at least in part, of about $80 \%$ of accidents on board. Human factors may include: the specific skill in performing any task, the level of attention (influenced by fatigue and mood), experience (which is not always a protective factor against accidents), adaptive capacity, attitudes, psychological factors; also age related changes in resistance to risk factor may occur $[6,7]$.

Another relevant cause to be considered is the role of stress on board. This is most likely the most relevant "human factor" responsible for influencing performance in sea work, and also the point where more can be done to prevent accidents on board. In fact, stress and psychological troubles were recognised by Maritime Labour Convention (MLC) 2006 as frequently involved in determining accidents on board [8]. It is not difficult to understand why life on board is so stressful. The seamen's work is tough, both from in terms of physical and psychological point of view, since in the last decades we have observed a shift from physical to mental work. Monitoring activities, steering, command, require a mental load. The higher the role and responsibility of seaman the higher the load; in many condition (adverse weather) a prolonged duty hours and a need for increased alertness may significantly increase the mental load. Many duties on board include shift-works (watchkeeping etc...) and this is a further source of stress as the work/rest cycle is could be impaired and sleep disturbances may occur [9]. Stress is caused also by the unfavourable environmental factors previously listed as the ship is a place of work and living at the same time, so the places and times for work and for rest are never completely separated. This lead to the fact that the seaman is never in a condition of complete relaxation; also leisure activities are limited by the confined spaces of a ship. Last but not least, the isolation of seamen should be considered. Seafarers are far from any social connection on land, away from their families and friend; they cannot choose their journey companions: so for weeks or months men coming from different countries, having different religions or simply different habits live and work together and this may easily lead to conflicts [9].

\section{CONCLUSIONS}

Our data indicate that the incidence of accidents on board ships is still high, and no reduction trend is taking place. Therefore the need of effective preventive measures is still unmet. Possible areas where to concentrate further efforts at this purpose may include continuous training and learning of maritime workers, based on the fact that many aspect of maritime work may change rapidly due to technical progress and the updating of regulations and safety procedures. Another aspect is the recruitment of maritime workers. In this respect more attention should be focused on psychological aspects of candidates, especially their temper and disposition and their capacity to adapt to unfavourable work conditions and to respond adequately to risk conditions

The reduction of stress on board, achieved by improving the environment, the quality of life on board, reducing the physical/mental burden of work, regulating shift-works and relax times should be always taken into account.

More information on the occurrence and type of accidents and on the body injured areas should represent the basis for developing strategies and campaigns for their prevention.

\section{ACKNOWLEDGEMENTS}

This work was supported in part by a grant of the Italian Ministry of Infrastructures and Transports. The author declares that there is no conflict of interest regarding the publication of this article.

\section{REFERENCES}

1. Amenta F, Dauri A, Rizzo N. Organization and activities of the International Radio Medical Centre (CIRM). J Telemed Telecare 1996; 2: $125-131$.

2. Rizzo N. Gli infortuni e loro prevenzione a bordo delle navi mercantili. Atti Sezione Studi CIRM, 1959; 3.

3. Rizzo N. Studio clinico-statistico sugli infortuni a bordo di navi mercantili. Atti Sezione Studi CIRM, 1967: 8.

4. Rizzo N, Amenta F. Accidents On board merchant ships. In: Cullen J, Siegrist J eds. Breakdown in Human Adaption to Stress. M. Nijhoff Publ., Boston 1984; pp. 469-483.

5. Grappasonni I, Petrelli F, Amenta F. Deaths on board ships assisted by the Centro Internazionale Radio-Medico in the last 25 years. Travel Med Infectious Dis 2012; 10: 186-191.

6. Grech M, Horberry T, Koester T, Human Factors In the Maritime Domain. CRC Press, Boca Raton, 2008.

7. Hetherington C, Flin R, Mearns K. Safety in shipping: the human element. J Safety Res 2006; 37: 401-411.

8. International Labour Organization. Maritime Labour Convention 2006. ILO, Geneva, 2006.

9. Carotenuto A, Molino I, Fasanaro AM, Amenta F. Psychological stress in seafarers: a review. Int Marit Health 2012; 63: 188-194. 